\title{
17
}

\section{Self assessment - A tool for business process reengineering}

\author{
A. Rolstadås
}

Norwegian Institute of Technology, Department of Production and Quality Engineering

R. Birkelands vei 2, 7034 Trondheim, Norway

Telephone: +4773593800

Telefax: +47 73597117

E-mail: arolst@protek.unit.no

\begin{abstract}
Industry experiences a changed competitive environment characterised by customer focus and global competition. To meet this situation manufacturing and development will have to be done globally as well. This is referred to as the virtual enterprise.

In the virtual enterprise performance becomes a key issue. Measurement of performance must be based on an extended productivity definition where productivity is the ratio between value added and resources consumed. This definition requires a process oriented approach. In this the definition and identification of business processes is essential. These processes must be studied and reengineered.

The study of business processes will include performance measurement. This can be done using the TOPP approach.

TOPP is a research programme where amongst other a model for productivity studies is developed. This model comprises system variables, functions, cycles and management philosophies.

Productivity studies can be done using the self assessment approach. This is either based on a questionnaire or on the definition and continuous evaluation of standard business processes.
\end{abstract}

\section{Keywords}

Production management, enterprise modelling, productivity, benchmarking. 


\section{THE GLOBAL COMPETITION}

Today industry places a major focus on manufacturing excellence and quality. The competitive environment has changed. It is not sufficient to be a cost champion for an enterprise to survive. Competition is experienced in several dimensions such as cost, time, quality and flexibility.

This changed competitive environment is of course based on a changed marked requirement. Some key characteristics for this new market situation are:

- Declining markets

- Global competition

- Customer in focus

- Life cycle requirements

- Environment protection restrictions.

The answer to this is the virtual enterprise (Kimura, 1993, Rolstadås, 1994).

This future enterprise is «lean» or «agile». The customer is in focus. All activities in the company must add value for the customer. Otherwise they represent a waste of resources. The customer worries about price, quality, service, and delivery. Total quality management has become a new topic addressing all these problems. Actually, it goes far beyond product quality. It looks at quality in every link and every activity. The customer's expectations must be exceeded.

Lean manufacturing is only possible with an efficient and lean production management. High quality must be secured at minimum cost and with the shortest possible delivery time.

The market is international. Each business process in the company must be benchmarked against the very best world wide (Rolstadås, 1993). But not only the market is international. The same is true for the company. A successful competitive company may place its development activities in region A and its manufacturing in regions B and C. These activities may be moved at any time to the region offering the most favourable conditions. The company will focus on its core business processes and may outsource the rest to more competitive suppliers.

These suppliers may have long term contracts including technological development. The company will establish a strategic alliance with its suppliers. This may even extend to the customers or vendors. This is what is meant by the virtual enterprise. It consists of a number of units geographically distributed but managed as one total unit although the subunits may be under separate management.

The competition leading up to the virtual enterprise can be understood by studying the stakeholders model depicted in Figure 1 (Rolstadås 1995). This model emphasises that the company is competing in several marketplaces. Long term survival and competitiveness is not limited to customers, but depends heavily on attractiveness towards the different stakeholders. In fact, most companies are competing about the best suppliers, the best lenders, the best alliance partner, the best employees etc. This competition is mainly a matter of position and terms in the relationship between company and stakeholder. 


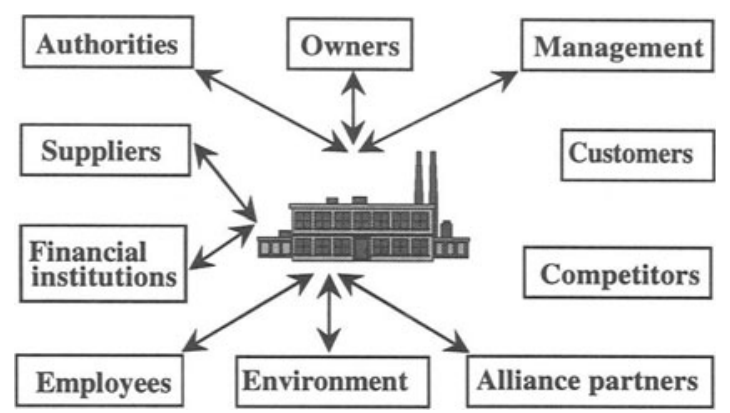

Figure 1 Stakeholders Model.

The new approach focuses on measuring performance rather than efficiency. However, this requires a process oriented view. The enterprise is considered as a set of interdependent business processes rather than a set of functions. To develop and change a company to this new philosophy requires a new way of thinking and some tools. Methods of enterprise modelling represent a foundation for implementing such a change and enterprise modelling techniques therefore becomes a crucial tool.

\section{PRODUCTIVITY VERSUS PERFORMANCE MEASUREMENT}

The classical definition of productivity is the ratio between output and input. Based on this definition, the classical approach to performance measurement has been published by Sink and Tuttle (Sink, 1985, Sink and Tuttle, 1989). The model claims that the performance of an organisational system is a complex interrelationship between the following seven performance criteria:

1. Effectiveness, doing the right things, at the right time, with the right quality, etc. Defining the criterion as a ratio, effectiveness can be defined as Actual Output/Expected Output. Figure 2 illustrates this.

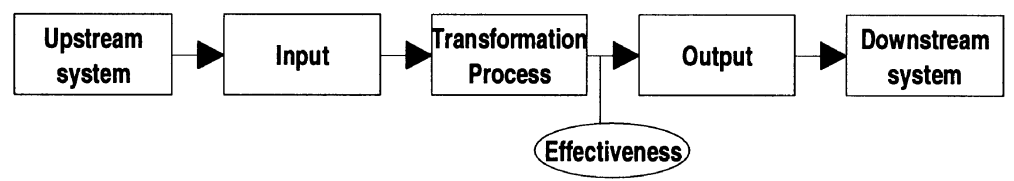

A.O.

E.O.

Figure 2 Operational Definition of Effectiveness. 
2. Efficiency, this is an input- and transformation process-question, defined as Resource Expected to Be Consumed/Resources Actually Consumed, as shown in Figure 3.

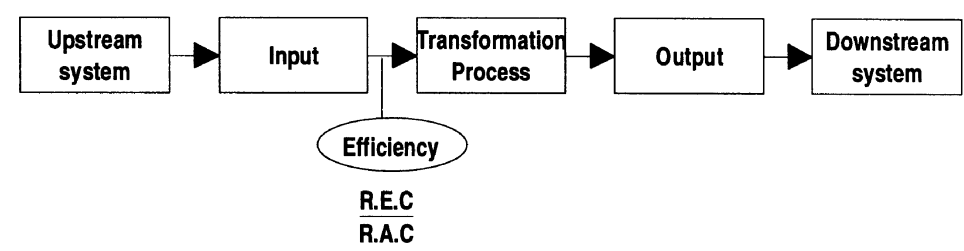

Figure 3 Operational Definition of Efficiency.

3. Quality, where quality is an extremely wide concept. To make things more tangible, quality could be measured at six checkpoints:

- Upstream systems

- Inputs

- Transformation value adding process

- Outputs

- Downstream systems

- Quality management process.

4. Productivity, this is the traditional ratio of Output/Input, but it appears as just one of several criteria. For an illustration, see Figure 4.

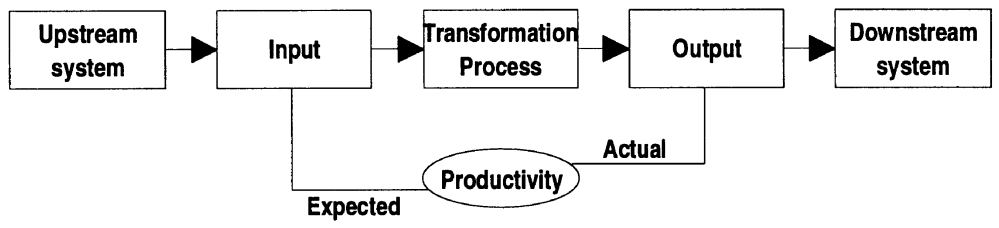

Figure 4 Operational Definition of Productivity.

5. Quality of work life, one essential, but often forgotten element contributing to a well performing system.

6. Innovation, a key element in sustaining and improving performance.

7. Profitability/Budgetability, the ultimate goal for any organisation. 
The traditional definition of productivity is insufficient to deal with the challenges the virtual enterprise will meet in the global market. For this purpose a new definition has to be applied. This will define productivity as the ratio between value added and resources consumed. This definition is much wider and includes all aspects of performance both inside the enterprise and in the supplier and customer markets. It is therefore more correct to talk about performance rather than productivity.

The performance oriented view requires a process oriented approach rather than a functional oriented approach. The process oriented thinking covers the interface between functional units in the enterprise in addition to the functions themselves. The process oriented approach therefore represents a more holistic thinking than the functional oriented approach.

\section{BUSINESS PROCESS ORIENTATION}

Process oriented thinking is by many considered as the new possibility for competitiveness improvement. By functional oriented thinking, only marginal improvement seems to be possible. The process oriented thinking includes two aspects (Rolstadås 1995):

- Definition of business processes

- Reengineering of business processes.

It could be questioned whether reengineering represents anything new. Some argue that the techniques behind reengineering are known form JIT and Time Based Management. Process flow analysis is a common denominator for several of these approaches. Actually, techniques and methods in reengineering are known from current management philosophies. Reengineering is not a streamlined concept with own tools, but a creative approach where the result is the only matter of concern. Tools and methods are adapted to suit this situation.

Reengineering is then simply a popular description for a strategy with a set of characteristics rather than a philosophy. However, people often tend to extend new buzzwords into independent philosophies.

Reengineering can be defined as (Camp, 1989):

Reengineering is fundamental rethinking and radical redesign of business processes to achieve dramatic improvements in critical, contemporary measures of performance, such as cost, quality, service, and speed.

The definition states that reengineering means search for dramatic change and productivity breakthrough. Reengineering is not the kind of tool a company applies if its performance needs a $10 \%$ boost. Business process reengineering is a strategic tool useful for achieving radical breakthroughs on business performance. Typical examples could be reduction of delivery times by $75 \%$, reduction of cycle times by $75 \%$, reduction of product development times by $50 \%$, reducing the number of components by $50 \%$ and so forth. Change in this magnitude is impossible by simply improving the individual performance. That is why strong adjectives as fundamental, radical and dramatic are used to describe the magnitude of change in the processes. This may be illustrated from the following list of bullet items (Rolstadås, 1995): 
- Customer orientation. Implementations should be justified from a customer perspective.

- Process orientation. Reengineering goes beyond predefined organisational boundaries and looks at the entire process to consider all tasks involved in transforming the input into output.

- Focus on core businesses. Reengineering is reserved for the main processes that could translate into value and give a competitive advantage.

- High ambition. Applying reengineering implicates an aim for breakthroughs, not evolution (60\% or higher).

- Rule-breaking. No traditional or established truth is allowed to be kept out from the reengineering process. Paradigms like specialisation, sequentiality, and timing have to be abandoned.

- Devotion for simplification. Complexity hides waste and simplification is necessary to increase speed and reduce costs.

- Creative use of information technology. Creative use of information technology in different ways. Reengineering is not the same as automation. The process is the core and information technology is just a tool to reinforce improvements.

- Rapid payback. Reengineering involves high risk due to the comprehensiveness and rapid payback is necessary to handle this.

It is not possible to describe a universal reengineered process. However, there exist some typical sources for action when reengineering a process (Camp, 1989, Carr, 1993).

- Several jobs are combined into one. Benefits from combining jobs could be fewer errors and misunderstanding, less handling, increased speed, and less administration.

- Decentralisation of decisions. Decisions should be made where the need for them arises.

- The steps in the process are performed in a natural order. Sequentalisation forced by the organisational structure is abandoned. Concurrent methods are applied when appropriate.

- Designing flexibility into all parts of new processes. Multiple versions of processes could be a solution.

- Work is performed where it makes the most sense. Reengineering boosts the traditional organisational structure and focuses on doing the activities as close to where they are required as possible. Support activities like detailed planning, quality assurance, purchasing etc. are adapted to enable decentralisation.

- Checks and controls are reduced. This is nonvalue-adding work and should be minimised.

- Reconciliation is minimised. This is done by cutting back the number of external contact points a process has in order to reduce the possibility that inconsistent data are received.

- A case manager provides a single point of contact. They act like a buffer between the process under reengineering and the customer.

- Hybrid centralised/decentralised operations are prevalent. Advantages of centralisation and decentralisation are combined in the same process. Information technology and empowered operators could make hybrid organisations possible. 
As it is clear from the preceding, there is no general definition of business processes. They are all adapted to the actual case.

The process oriented approach is ideal for studying the performance of an enterprise. Such performance studies can be done at three levels:

- Self assessment

- External evaluation

- Benchmarking.

Self assessment means that the enterprise evaluates itself over time. It must be based on a model of the enterprise, defining business processes.

External evaluation involves external experts to review the performance of the enterprise compared to what the expert perceives as best practice. Again this will have to be based on a similar enterprise model as for self assessment.

Benchmarking is extending the external evaluation to compare selected business processes with such processes in other enterprises that can demonstrate best practice or clear performance excellence.

\section{THE TOPP PROGRAMME}

TOPP is a research programme sponsored by the Norwegian Research Council (Moseng, Bredrup, 1993). The overall goal of TOPP is to «Focus on the total productivity for the whole enterprise and stimulate an industrial climate that improves competitiveness».

Important key objectives and key issues are:

- Time to market

- Quality

- Flexibility

- Total cost.

The programme involves co-operation between

- The Federation of Norwegian Engineering Industries

- The Norwegian Institute of Technology

- Industrial enterprises,

and is sponsored by

- The Research Council of Norway. 
The TOPP programme is planned for the period 1992-95. The following tasks are included:

- Analysing company productivity and competitiveness

- Implementing actions for industrial productivity improvements (industrial projects, seminars, courses, industrial networks, etc.)

- Generating new knowledge (research projects, analysing productivity data, etc.)

- Long term competence programme.

TOPP is bases on an enterprise model. This is again based on the FOF model (Wortmann, 1989, Falster, 1991) indicating performance by effect on performance indicators as design choices are changed. In TOPP the design choices are called system variables.

The following system variables are considered:

- Products

- Facilities

- Equipment

- Personnel

- Organisation and systems.

To study an enterprise, it is necessary to look at functions performed on the system variables. To represent these functions, the value adding chain defined by Porter may be suitable. However, since TOPP addresses the manufacturing industry, it can be made more specific as shown in Figure 5.

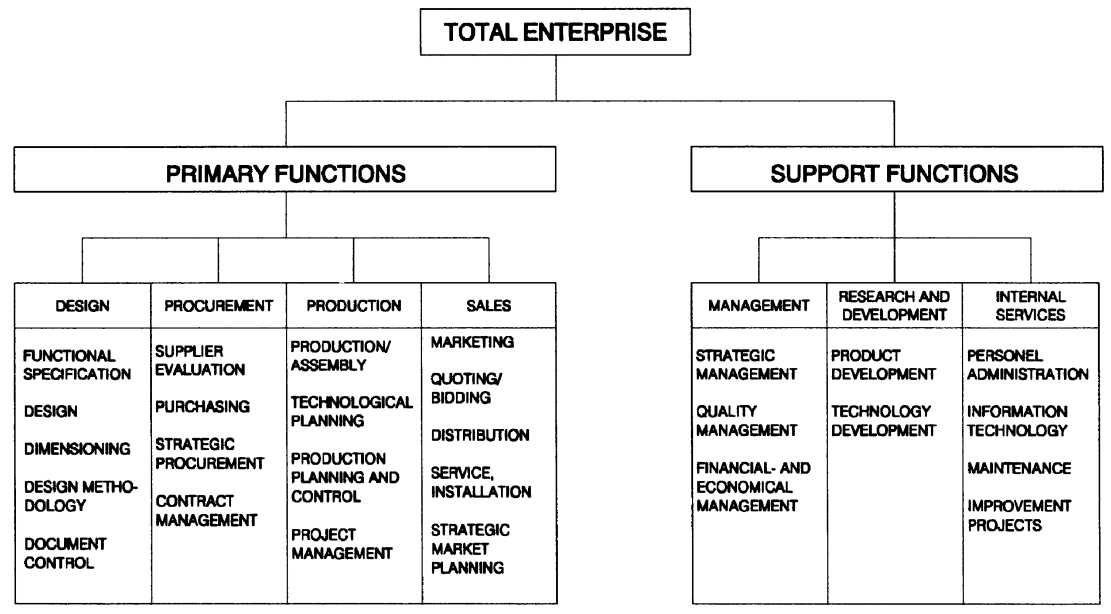

Figure 5 Functions in the Value Adding Chain (Moseng, Bredrup, 1993). 
The description of the functions along the value adding chain (Figure 5) represents a static picture of the company. For a study of productivity performance, this may be insufficient. An enterprise may be «world champion» within each function, but it may still be less competitive. The reason is, of course, what is happening on the transfer from one function to another and how functions may be run concurrently. This more dynamic aspect may be taken into account by following the various flows in the company. These flows are referred to as cycles. A possible set of cycles could be:

- Material cycle (follow materials through the enterprise)

- Order cycle (follow a customer order through the company)

- Product cycle (follow a product through its whole life from idea to destruction)

- Supplier cycle (follow all steps through the interface between the enterprise and a supplier for a purchase)

- Customer cycle (follow all steps through the interface between the enterprise and a customer for a sales order).

It may be sufficient to study system variables, functions and cycles. However, TOPP has added a fourth dimension to this: management philosophies. A management philosophy is a way of thinking and an object of focus that will affect the total performance of the company. Examples of such management philosophies are:

- Total Quality Management

- Just in Time

- Continuous Improvement

- Customer Satisfaction

- Time Based Management

- Zero Defects

- Zero Inventories

- Concurrent Engineering

- Management by Objectives

- Partnership and Strategic Alliances.

\section{TOPP SELF ASSESSMENT}

The TOPP self assessment is based on the TOPP model described in the preceding and a set of 22 general business processes shown in table 1.

There are two different approaches to self assessment:

- Questionnaire

- Process evaluation. 
The first approach uses a questionnaire in standard format to be answered by the enterprise. This questionnaire consists of three parts (TOPP, 1992):

- Part 1

Facts about the company such as products, equipment, human capital, finance, costs, customers, etc.

- Part 2

Overall evaluation of different functions and system variables to be answered confidentially by a limited number of employees at different levels in the organisation.

\begin{tabular}{|l|l|l|}
\hline $\begin{array}{l}\text { Process } \\
\text { no. }\end{array}$ & $\begin{array}{l}\text { Types of } \\
\text { process }\end{array}$ & Process \\
\hline 1 & & Sales and marketing \\
2 & & Procurement \\
3 & & Technological planning \\
4 & & Design and engineering \\
5 & Production planning and control \\
6 & & Production and assembly \\
7 & & Distribution \\
8 & & Order processing \\
9 & & Invoicing and reimbursement \\
\hline 10 & & Strategic management \\
11 & & Financial management \\
12 & Support & Personnel administration \\
13 & & Information management \\
14 & & Maintenance \\
15 & & Internal control of health, environment and safety \\
\hline 16 & & Continuous improvement \\
17 & & Market development \\
18 & & Product development \\
19 & Development & Technology development \\
20 & & Human resource development \\
21 & & Supplier development \\
22 & & Development of external relations \\
\hline
\end{tabular}

Table 1 General Business Processes in the TOPP Self Assessment Model.

\section{- Part 3}

Detailed evaluation of primary and support functions and system variables. This part is answered by expert groups in the company. Management is represented in all groups. 
The scale of assessment comprises an interval from 1 to 7 with 7 as «best practice». Based on the response to the questionnaires, four types of reports are provided:

1. Individual report based on data from own company

2. Report based on data from all participating companies

3. Report based on data from groups of companies. Criteria for selection of groups could be competitors, products, production technology, etc.

4. Results from research. An R\&D programme is established to analyse the total database to search for success factors, etc.

The second approach to self assessment uses the defined business processes in table 1 . The enterprise will carry out this evaluation without any external assistance. The objective is to follow and monitor trends in performance to obtain a continuous improvement.

The methodology consists of the following steps (TOPP, 1994):

a) Identification of critical and important business processes in the company

b) Selection of analysing areas and indicators to measure the business processes

c) How to organise the self assessment

d) Collection of data

e) Presentation of results

f) Evaluation of results, actions.

\section{REFERENCES}

Camp, R.C. (1989) Benchmarking-The Search for Industry Best Practices That Lead to Superior Performance. ASQC Quality Press.

Carr, D.K. (1993) Managing for Effective Business Process Redesign. Journal of Cost Management, 7 (3).

Falster, P., Rolstadås, A., Wortmann, H. (January 1991) FOF Production Theory, WP2 Report: Design of a Conceptual Model. Trondheim.

Kimura, F. (1993) Virtual Manufacturing Environment. IMS Globemann 21 Meeting, Kyoto.

Moseng, B., Bredrup, H. (1993) A Methodology for Industrial Studies of Productivity Performance. Production Planning \& Control, vol. 4, no. 3.

Rolstadås, A. (1993) Manufacturing Industry Benchmarking. APMS'93. Elsevier Science Publishers.

Rolstadås, A. (1994) Beyond Year 2000-Production Management in the Virtual Company. IFIP WG5.7 Conference on Evaluation of Production Management Methods, Gramado, Brazil, March 1993. Elsevier Science Publishers.

Rolstadås, A. (Ed) (1995) Performance Management-A Business Process Benchmarking Approach. Chapman \& Hall.

Sink, D.S. (1985) Productivity Management: Planning, Measurement, and Evaluation, Control, and Improvement. John Wiley \& Sons, New York.

Sink, D.S. and Tuttle, T.C. (1989). Planning and Measurement in Your Organisation of the Future. Industrial Engineering and Management Press, Norcross. 
TOPP, (1992) TOPP-A Productivity Program for Manufacturing Industries, Questionnaire for Analyzing Competitiveness. University of Trondheim, Trondheim, Norway.

TOPP, (1994) Handbook for Self Assessment, University of Trondheim, Trondheim, Norway.

Wortmann, J.C. (1989) Towards an Integrated Theory for Design, Production, and Production Management of Complex, One of a Kind Products in Factory of the Future. Commission of the European Communities (ed.), ESPRIT'89, Proc. 8th Annual Esprit Conf., Kluwer Academic Publishers, Dordrecht. 